\title{
REVIEW
}

\section{Ramelteon: a Review of its Therapeutic Potential in Sleep Disorders}

Seithikurippu R. Pandi-Perumal · Venkatramanujam Srinivasan · D. Warren Spence · Adam Moscovitch • Rüdiger Hardeland · Gregory M. Brown · Daniel P. Cardinali

Received: May 14, 2009 / Published online: July 3, 2009 / Printed: July 10, 2009

(C) Springer Healthcare Communications 2009

\section{ABSTRACT}

Ramelteon is a tricyclic synthetic analog of melatonin that acts specifically on $\mathrm{MT}_{1}$ and $\mathrm{MT}_{2}$ melatonin receptors. Ramelteon's halflife is longer than that of melatonin, being metabolized in the body to four main metabolites, M-I, M-II, M-III, and M-IV. M-II has an

S.R. Pandi-Perumal $(\bowtie)$

Somnogen Inc, 8790 112th Street, Richmond Hill,

New York, NY 11418-2317, USA

Email: sleepresearch@gmail.com

Venkatramanujam Srinivasan

Sri Sathya Sai Medical, Educational and Research

Foundation, Prashanthi Nilayam 40, Kovai Thirunagar

Coimbatore - 641014, India

D. Warren Spence

Sleep and Alertness Clinic, 750 Dundas Street West, Toronto, ON M6J 3S3, Canada

Adam Moscovitch

Canadian Sleep Institute and CSI Research Center,

1 Codsell Ave, Toronto, ON M3H 3V6, Canada

Rüdiger Hardeland

Institute of Zoology and Anthropology, University

of Goettingen, Berliner Str. 28, D-37073

Goettingen, Germany

Gregory M. Brown

Department of Psychiatry, Faculty of Medicine,

University of Toronto, 100 Bronte Rd. Unit 422,

Oakville, Ontario, L6L 6L5, Canada

Daniel P. Cardinali

Departamento de Docencia e Investigación, Facultad de Ciencias Médicas, Pontificia Universidad Católica Argentina, C1107AFD Buenos Aires, Argentina affinity to $\mathrm{MT}_{1}$ and $\mathrm{MT}_{2}$ of about one-tenth of the parent compound, but its concentration in the circulation exceeds that of ramelteon by more than an order of magnitude. Ramelteon is effective in decreasing latency to persistent sleep and increasing total sleep time in freely moving monkeys. A number of clinical studies have been undertaken to study the efficacy of ramelteon in subjects with chronic insomnia. In almost all of these studies, ramelteon, in various doses of 4,8 , or $16 \mathrm{mg}$ most commonly, significantly reduced sleep latency and increased sleep duration. Its primary action in sleep promotion is not a generalized gamma-aminobutyric (GABA)-ergic central nervous system depression, but rather it acts as a melatonergic agonist in the suprachiasmatic nucleus (and at other central nervous system sites), from where downstream processes, including GABA-ergic effects, are controlled via the hypothalamic sleep switch. Unlike other commonly prescribed hypnotic drugs, ramelteon is not associated with next morning hangover effects or reductions in alertness, nor has it been shown to cause withdrawal symptoms. The adverse symptoms reported with ramelteon are mild. All long-term investigations that have been carried out support the conclusion that 
ramelteon is a well tolerated and effective drug for the treatment of insomnia.

Keywords: hypnotic; insomnia; melatonin; ramelteon

\section{INTRODUCTION}

Melatonin, the major hormone secreted by the pineal gland, was first identified by Lerner in 1958. This hormone has a number of important physiological functions including regulation of circadian rhythms, sleep promotion and consolidation, ${ }^{1}$ anti-oxidative defense, ${ }^{2-4}$ immune regulation and aging, ${ }^{5,6}$ control of reproductive activity, ${ }^{7,8}$ and suppression of tumor growth. ${ }^{9,10}$

The secretion of melatonin is greatest during the dark hours of the night, an effect so consistently expressed that it is now considered to be the chemical signal indicating the length of darkness. ${ }^{11}$ As the highest levels of melatonin secretion occur during the nighttime in diurnally active vertebrates, it has been suggested that melatonin has a crucial role in sleep promotion, at least in this group of organisms. Owing to its involvement in the regulation of circadian rhythms, any disruption in melatonin secretion may play an important part in the etiology of circadian rhythm sleep disorders (CRSD). This has consequently led to advocacy for exogenous melatonin use in the treatment of CRSD. ${ }^{12-16}$ Melatonin is also being widely used as a natural supplement or, in its analog variants, as a drug for various sleep disorders, including the (self-) treatment of insomnia. ${ }^{17-20}$

\section{MANAGEMENT OF INSOMNIA}

Insomnia is one of the most frequently reported complaints in clinical practice and affects $30 \%-40 \%$ of the adult population. ${ }^{21}$ It most commonly occurs in elderly individuals, ${ }^{22,23}$ in patients with depression, ${ }^{24}$ and in those with dementia and neurodegenerative disorders. According to a National Sleep Foundation survey (USA), 75\% of the adults in the USA have at least one symptom of a sleep disorder and $54 \%$ have one symptom related to insomnia. ${ }^{25}$ Treatment for insomnia includes both nonpharmacologic and pharmacologic treatments. Selection of an appropriate antiinsomnia therapy is based upon a number of factors such as age, the nature of the disease, response to current medications, etc. A number of nonpharmacologic therapies including cognitive behavioral therapy, relaxation therapy, yoga, stimulus control therapy, and sleep-hygiene education have all been employed for treatment of insomnia and have been variously found effective in certain cases. ${ }^{26,27}$ Drugs such as triazolam or zolpidem that act as benzodiazepine receptor agonists (BzRAs) and that modulate gamma-aminobutyric $A\left(G_{A B A}\right)$ receptor function in the brain are used widely for treating insomnia. ${ }^{28}$ The antidepressant trazodone is also commonly prescribed for the condition. These drugs, however, have been linked to a number of side effects.

Benzodiazepines (BZDs) are associated with cognitive and memory impairment, ${ }^{29}$ while trazodone has been shown to cause cardiac rhythm disturbances and orthostatic hypotension. ${ }^{30}$ Drugs without these side effects would certainly benefit not only elderly individuals with insomnia but also a number of other patients with this condition.

\section{Melatonin in Insomnia}

Sleep disturbances, which are frequently observed in the elderly, have been related to low nocturnal melatonin production that is seen in most individuals of advanced age. ${ }^{31}$ Melatonin's sleep-promoting activity has 
indeed been demonstrated both in animals and humans. Melatonin has been shown to reduce sleep onset latency (SOL) and to increase sleep efficiency when administered in the evening to healthy adults in doses ranging from 0.3 to $1 \mathrm{mg} .{ }^{32,33}$ Brain imaging studies of awake subjects have shown that melatonin modulates brain activity patterns to resemble those of actual sleep. ${ }^{34} \mathrm{~A}$ number of double-blind, placebo-controlled studies have demonstrated that melatonin is suitable as a hypnotic drug. In a study undertaken with 13 patients, ranging in age from 25 to 65 years, administration of $75 \mathrm{mg}$ of melatonin for 7 days significantly increased the subjective report of total sleep time (TST) and daytime alertness when compared with placebo; ${ }^{35}$ however, the dose of melatonin administered was high. In another study, a low dosage of melatonin was used. In this double-blind placebo-controlled study of 10 patients, administration of melatonin in $1 \mathrm{mg}$ and $5 \mathrm{mg}$ doses significantly improved the overall subjective quality of sleep and promoted an earlier onset of sleep. Rapid eye movement onset latency was also delayed in this study. ${ }^{36}$

Melatonin administration $(5 \mathrm{mg} /$ fast-release tablets) was found to improve sleep quality in seven of 15 patients with insomnia who had been resistant to treatment with BZDs and zopiclone. ${ }^{37}$ In two separate groups of elderly patients with insomnia (mean age $73.1 \pm 5.2$ years, eight patients; and $81.1 \pm 8.9$ years, 18 patients), administration of $2 \mathrm{mg}$ fast-release melatonin improved sleep efficiency $(P<0.05) .{ }^{38}$ Similarly, in a randomized, double-blind, placebocontrolled crossover study of 12 elderly individuals with chronic insomnia (aged $76 \pm 3.9$ years), administration of $2 \mathrm{mg}$ prolonged-release melatonin for 3 weeks followed by placebo resulted in significant improvement of sleep efficiency $(P<0.001)^{39}$ (This formulation has just been approved for the treatment of elderly individuals with insomnia by the European Medicines Agency [EMEA].) In one study the efficacy of melatonin on sleep was evaluated in 25 patients (mean age $37.3 \pm 15.3$ years) who had delayed sleep phase syndrome (DSPS). Polysomnography (PSG) revealed that melatonin in $5 \mathrm{mg}$ doses significantly improved sleep quality without altering sleep architecture. ${ }^{40}$ In PSG studies of 20 patients with DSPS, melatonin in doses of $5 \mathrm{mg}$ /day for 4 weeks significantly decreased sleep latency when compared with placebo. ${ }^{41}$ Although in general published studies have employed only small numbers of patients, a meta-analysis of 17 studies clearly indicated that melatonin preparations produced statistically significant benefits in SOL, sleep efficiency, and sleep duration. ${ }^{42}$

\section{Melatonin in the Regulation of Sleep: Possible Mechanisms of Action}

Melatonin's hypnotic and chronobiotic effects are believed to be primarily exerted via $\mathrm{MT}_{1}$ and $\mathrm{MT}_{2}$ receptors located in the circadian pacemaker, the suprachiasmatic nucleus (SCN) of the anterior hypothalamus. ${ }^{43-45} \mathrm{SCN}$ neurons express high concentrations of both melatonin receptors, although both receptors are also found widely in the central nervous system. While the principal $\mathrm{MT}_{2}$-mediated actions in the $\mathrm{SCN}$ are related to circadian phase shifts and comprise activations of protein kinase $\mathrm{C}^{46,47}$ (an index of increased cell activity), signaling via $\mathrm{MT}_{1}$ leads primarily to suppression of the electrical activity of SCN neurons. ${ }^{48,49}$ It is, therefore, likely that the hypnotic effects of melatonin that are not associated with phase shifting are mediated by $\mathrm{MT}_{1}$. The role of SCN in the control of sleep has been well studied in various species. It is, however, important to make a clear distinction between sleep induction as well as maintenance of sleep at appropriate circadian phases and 
phase shifting. In squirrel monkeys, a diurnal species like humans, the circadian signal produced by the SCN promotes wakefulness during subjective day and consolidation of sleep at night. SCN lesions have been found to disrupt the consolidation of the sleep-wake cycle. ${ }^{50}$ The circadian rhythm of melatonin secretion also regulates core body temperature, a function that is known to influence sleep. ${ }^{1,51}$

Melatonin's hypnotic effect has been shown to depend on the circadian phase of administration. As shown by Stone et al. ${ }^{52}$ in a doubleblind, placebo-controlled study, melatonin administered at night (11:30 PM) had no significant effect on nighttime sleep in healthy individuals, whereas its administration in the evening (6:00 PM) exerted hypnotic activity. Although the exact reason for this difference is not known, melatonin levels in the cerebrospinal fluid of the third ventricle, which are nearly 20 times higher than those found in the circulation, were assumed to be responsible for the variations of melatonin's action in the brain. ${ }^{53,54}$ Despite the evidence of these cited reports on melatonin's hypnotic actions, its efficacy in promoting sleep efficiency has been questioned, especially as most of the results have shown only borderline significance or are otherwise difficult to evaluate because of methodological inconsistencies. ${ }^{55}$ The poor outcomes concerning sleep efficiency or TST have been attributed to melatonin's short half-life (of less than 30 minutes) in the circulation. It has therefore been suggested that a melatonergic agonist with a longer half-life and, thus, an enhanced bioavailability, would saturate $\mathrm{MT}_{1}$ and $\mathrm{MT}_{2}$ receptors in the SCN more efficiently and for a longer duration of time. It has consequently been further suggested that such an agonist might be of greater benefit than melatonin in promoting sleep efficiency in patients with insomnia. ${ }^{54}$

\section{RAMELTON, A MELATONERGIC AGONIST WITH SLEEP PROMOTING PROPERTIES}

Ramelteon $\{(\mathrm{S})-\mathrm{N}-[2-(1,6,7,8$-tetrahydro-2Hindeno[5,4-b]furan-8-yl)ethyl] propionamide; TAK-375\} is a novel melatonin receptor agonist that has been shown to be selective for $\mathrm{MT}_{1}$ and $\mathrm{MT}_{2}$ receptors, but without affinity for the melatonin-binding quinone reductase 2, previously called $\mathrm{MT}_{3} \cdot{ }^{56,57}$ Ramelteon has no affinity for GABA-ergic, dopaminergic, opioidergic, nor any other major CNS receptors, binding sites of neurotransmitters or neuropeptides, regulatory enzymes, or ion channels. ${ }^{56,57}$ However, various additional nonmembrane-binding sites of melatonin remain to be tested. ${ }^{58}$

\section{Pharmacokinetics of Ramelteon}

In-vitro binding studies have shown that ramelteon's affinity for $\mathrm{MT}_{1}$ and $\mathrm{MT}_{2}$ receptors is 3-16 times higher than that of melatonin itself. Although ramelteon has a relatively short half-life (1.2 hours), it is, however, substantially longer than that of melatonin. ${ }^{56}$ When administered orally, ramelteon is absorbed rapidly in fasting conditions and reaches its peak concentration in plasma in 45 minutes, which ranges from 30 minutes to 1.5 hours. The total absorption of this drug is $84 \%$, but its total bioavailability is only $1.8 \%$. After administration of the therapeutic dose $(8 \mathrm{mg})$, the peak plasma concentration of ramelteon increases up to $57,000 \mathrm{pg} / \mathrm{mL}^{59}$

Ramelteon is metabolized by oxidation to hydroxyl and carbonyl derivatives and is eliminated within 96 hours after oral administration. It is metabolized in humans to four metabolites: M-I, M-II, M-III, and M-IV. M-II is the major metabolite of ramelteon followed by M-IV, M-I, and M-III. M-II exhibits a selectivity for 
melatonin $\mathrm{MT}_{1}$ and $\mathrm{MT}_{2}$ receptors that is similar to that of the parent compound; however, it has an affinity of only $10 \%$ of that of ramelteon. ${ }^{56}$ M-II attains plasma concentrations 20-100-fold (average about 30-fold) greater than that of the parent compound, ${ }^{60} \mathrm{M}$-II, which is formed by the cytochrome P450 subform CYP1A2, and has a half-life of 2-4 hours in the circulation, a value that only partially explains the differences in concentration. Despite the lower receptor affinity, the considerably higher blood levels of M-II support the hypothesis that this metabolite should substantially contribute to ramelteon's overall activity, ${ }^{60}$ and may enhance its sleeppromoting efficacy. Ramelteon clearance has often been shown to be significantly reduced in elderly subjects, an effect that is not significantly influenced by gender. In view of the extended persistence of M-II in the circulation, the pharmacokinetics of the drug should not be primarily judged on the basis of ramelteon clearance alone. This is one of the most unusual pharmacokinetic properties of ramelteon.

\section{Ramelteon: Sleep-Promoting Actions in Primate Studies}

In a study conducted in young adult female monkeys ( $n=22)$ (Macaca fascicularis), cortical electroencephalography, electromyography, and electrooculography were recorded. ${ }^{61}$ Individual monkeys received, at 6:00 $\mathrm{PM}$, different doses of ramelteon $(0.003,0.03$, and $0.3 \mathrm{mg} / \mathrm{kg}$ ) and, correspondingly, other animals were treated at the same circadian phase with different doses of melatonin $(0.3,1$, and $3 \mathrm{mg} / \mathrm{kg})$. For comparison, zolpidem was also administered to other experimental groups $(1,3,10$, and $30 \mathrm{mg} / \mathrm{kg})$. The study demonstrated that ramelteon, in doses of 0.03 and $0.3 \mathrm{mg} / \mathrm{kg}$, was effective in reducing the time to sleep onset as compared with controls. Ramelteon, in these two doses, also significantly increased the total duration of sleep. Melatonin ( 1 and $3 \mathrm{mg}$ doses) also tended to increase the total duration of sleep, but without attaining statistical significance. Zolpidem, in none of the doses tested $(1,3,10$, and $30 \mathrm{mg} / \mathrm{kg})$, had any effect on the latency to slow wave sleep, nor on TST. The investigators concluded that ramelteon reduced the SOL and increased sleep duration in freely moving monkeys without producing the side effects often seen with BzRAs. ${ }^{61}$ In another study in monkeys, ramelteon did not promote physical dependence, ${ }^{62} \mathrm{a}$ finding of particular importance for judging the usefulness of the drug.

\section{Ramelteon's Effects on Sleep: Clinical Studies}

The efficacy, safety, and dose-response of ramelteon were evaluated by Erman et al. ${ }^{63}$ in a multicenter clinical trial. One hundred and seventeen patients with chronic primary insomnia were studied in 13 centers in a double-blind, randomized, crossover investigation, which took place over a 5 -year period. The mean age of the enrolled patients was 37.7 years. Each patient was randomized to a dose sequence of $4,8,16$, and $32 \mathrm{mg}$ ramelteon or placebo. Each patient underwent five 2-day treatment periods. The investigators found that all doses of ramelteon resulted in statistically significant reductions in latency to persistent sleep (LPS) and increased sleep duration, as measured by PSG. ${ }^{63}$ Further, it was noted that ramelteon did not produce any residual sedation, nor psychomotor nor memory impairment. Of the 117 patients studied, 103 completed the study. The reasons given for premature withdrawal were not directly related to drug use. In the subjects that completed the study, all doses of ramelteon $(4,8,16$, and $32 \mathrm{mg}$ ) resulted in statistically significant reductions in LPS $(P<0.001)$ and increases in TST $(P<0.05)$. Patients with a higher LPS at screening 
(>66.5 minutes) experienced more reductions in the time to reach persistent sleep. Mean LPS was 26.2-29.8 minutes across treatment groups as compared with 48.8 minutes for placebo $(P<0.001)$. In contrast, in patients with a shorter screening LPS ( $<66.5$ minutes) the LPS was 15.721.8 minutes across treatment groups as compared with 26.2 minutes for placebo $(P<0.05)$. Similarly, the group of patients with a screening TST less than 358 minutes showed greater improvements than did the group whose screening was greater than 358 minutes. ${ }^{63}$ All ramelteon doses resulted in similar improvements suggesting that ramelteon promotes sleep in a manner that differs from that of other hypnotics. More specifically, ramelteon activates $\mathrm{MT}_{1}$ receptors in the SCN to attenuate the circadian wakepromoting signal, thus allowing the homeostatic sleep load to promote sleep. ${ }^{63}$

Roth et al. ${ }^{64}$ investigated the subjective efficacy of ramelteon in 829 elderly outpatients (mean age of 72.4 years) with chronic insomnia. Of the initially selected sample, 128 patients were discontinued. In a double-blind study ramelteon was administered in doses of 4 or $8 \mathrm{mg}$ /day for a period of 5 weeks in comparison with placebo. Discontinuation was approximately equal between groups being due most commonly to a lack of efficacy (placebo, $n=17$; ramelteon $4 \mathrm{mg}, n=14$; and ramelteon $8 \mathrm{mg}, n=9$ ), protocol deviation (placebo, $n=10$; ramelteon $4 \mathrm{mg}$, $n=15$; and ramelteon $8 \mathrm{mg}, n=10$ ), and adverse events (placebo, $n=8$; ramelteon $4 \mathrm{mg}, n=8$; and ramelteon $8 \mathrm{mg}, n=7)$. Compared with the placebo group, patients in both ramelteon groups reported statistically significant reductions in SOL (16\%-35\%) at the end of week 1 and week 5. Also, in this study a greater treatment effect was found in patients who had a high baseline sleep latency ( $>67.1$ minutes). The overall median of baseline sleep latency (>67.1 minutes) was used as the cut-off value. The superiority of ramelteon over placebo in reducing sleep latency was consistently demonstrated at every dose level and time period that were evaluated:

- At week 1-for 4 mg: 93.1 minutes with ramelteon vs. 107.0 minutes with placebo $(P=0.013)$; for $8 \mathrm{mg}$ : 90.2 vs. 107.0 minutes $(P=0.003)$.

- $\quad$ At week 3-for 8 mg: 79.3 vs. 96.5 minutes $(P=0.004)$.

- $\quad$ At week 5-for 4 mg: 83.6 vs. 98.2 minutes $(P=0.015)$; for $8 \mathrm{mg}: 74.9$ vs. 98.2 minutes $(P<0.001)$.

Increases in TST were observed in both ramelteon groups at week $1(P=0.004)$ and week 3 $(P=0.055)$. At week 1 , for $4 \mathrm{mg}$ of ramelteon the effect was 324.6 vs. 313.9 minutes with placebo $(P=0.004)$; for $8 \mathrm{mg}$ : 321.1 vs. $313.9 \mathrm{~min}-$ utes $(P=0.055)$. At week 3 , for $4 \mathrm{mg}$ of ramelteon the effect was 336.0 vs. 324.3 minutes $(P=0.007)$; for $8 \mathrm{mg}$ : 332.1 vs. 324.3 minutes $(P=0.071)$. These results were consistent with patient reports of enhanced sleep quality and of feeling refreshed upon arising in the morning findings also in agreement with PSG studies on ramelteon. ${ }^{65}$ Sleep promotion by ramelteon was dose-independent as in a previous study. ${ }^{65}$ This study also supports the finding that ramelteon is a chronohypnotic agent with a specific action on $\mathrm{MT}_{1}$ and $\mathrm{MT}_{2}$ receptors in the SCN that are involved in the normal regulation of a sleepwake cycle.

In a clinical study on 100 elderly patients drawn from 17 sleep centers, ramelteon in doses of $4 \mathrm{mg}$ /day increased patients' TST ( $P=0.036)$ and sleep efficiency $(P=0.037)$ and shortened the LPS $(P=0.001) .^{65}$

The effects of differing doses of ramelteon were studied by Zammit and coworkers ${ }^{66}$ in another multicenter, double-blind, placebocontrolled study. The investigators used PSG to evaluate the effects of ramelteon $8 \mathrm{mg}$ and $16 \mathrm{mg}$ on 405 patients with chronic insomnia. A total of 
371 patients completed the double-blind study and 267 completed the single-blind follow-up. During the double-blind treatment period discontinuation was due to adverse events $(n=6)$, lack of efficacy $(n=2)$, protocol deviation $(n=6)$, withdrawal of consent $(n=18)$, lost to follow-up $(n=1)$, and withdrawn because of noncompliance $(n=1)$. During a single-blind runout period after treatment four subjects were lost: discontinued treatment due to adverse event $(n=1)$, withdrawal of consent $(n=1)$, protocol deviation $(n=1)$, and one subject missed visit 5 due to work-related travel. LPS was significantly reduced with ramelteon $8 \mathrm{mg}$ (32.2 minutes) or $16 \mathrm{mg}$ (28.9 minutes), when compared with placebo (47.9 minutes). These effects were maintained following 3-5 weeks (after ramelteon was discontinued). Both doses of ramelteon also prolonged total duration of sleep. ${ }^{66}$

In a related study involving a larger population (289 adults), the efficacy and safety of ramelteon, $8 \mathrm{mg}$ and $16 \mathrm{mg}$ per day, was evaluated. ${ }^{67}$ Compared with placebo, ramelteon at $8 \mathrm{mg}$ significantly reduced PSG measures of LPS (12.2-19.7 minutes, $P=0.004)$. TST was significantly increased by ramelteon at both $8 \mathrm{mg} /$ day (436.8 minutes, $P=0.009$ ) and $16 \mathrm{mg} /$ day (433.1 minutes, $P=0.043) .{ }^{67}$ In another 5-week, double-blind, controlled study carried out by Takeda Pharmaceuticals, Illinois, USA, the effects of $8 \mathrm{mg} /$ day doses of ramelteon were evaluated in 270 patients with chronic insomnia. ${ }^{68}$ Ramelteon $8 \mathrm{mg} /$ day was associated with reductions in LPS at week 1 (63\% for ramelteon vs. $39.7 \%$ for placebo; $P<0.001$ ), week 3 (ramelteon $63 \%$ vs. placebo $41.2 \% ; P<0.01$ ), and week 5 (ramelteon $65.9 \%$ vs. placebo $48.9 \%$; $P<0.05)$. The improvement in LPS, which was evident from the first week, was sustained until week 5, without associated withdrawal effects or rebound insomnia. ${ }^{68}$
In a longitudinal study ramelteon $8 \mathrm{mg} /$ day improved sleep in the first week, but was associated with somewhat mixed effects at later stages of the study. The drug was nevertheless well tolerated by the sample with chronic insomnia. ${ }^{69}$

A recently published pooled analysis included four randomized, double-blind, placebocontrolled clinical trials of ramelteon in 566 adult patients with chronic insomnia who took ramelteon $8 \mathrm{mg}$ as compared with 556 patients with insomnia who took placebo. ${ }^{70}$ Ramelteon reduced LPS on nights 1 and 2 by 13 minutes more than placebo in adults with chronic insomnia. At nights 1 and 2 the mean LPS for the ramelteon $8 \mathrm{mg}$ group was $30.2 \mathrm{~min}$ utes, which was significantly less than the mean LPS for the placebo group at 43.3 minutes $(P<0.01)$, thus substantiating the clinical efficacy of ramelteon in promoting sleep.

The effectiveness and tolerability of ramelteon was also examined in adult patients with generalized anxiety disorder and insomnia symptoms in an open-label study, including 27 adults with sleep disturbance meeting DSM-IV diagnostic criteria. ${ }^{71}$ After 12 weeks a significant symptom reduction was observed on all scales, with patients falling asleep faster and sleeping longer; the data suggesting that ramelteon may be an effective treatment for insomnia symptoms in generalized anxiety disorder.

In a 6-month randomized, double-blind, placebo-controlled study carried out in 46 centers in the USA, Europe, Russia, and Australia, 451 adults (age $\geq 18$ years) with chronic primary insomnia received ramelteon $8 \mathrm{mg}$ or placebo 30 minutes before bedtime. ${ }^{72}$ Sleep was evaluated by PSG and morning questionnaires on the first 2 nights of week 1; the last 2 nights of months 1, 3, 5, and 6; and nights 1 and 2 of the placebo run-out. Over the 6 months of treatment, ramelteon consistently reduced LPS compared with baseline 
and with placebo with no significant next morning residual effects, withdrawal symptoms, or rebound insomnia.

Sleep disturbances have been reported to be one of the most troubling manifestations of menopause. ${ }^{21}$ In 20 healthy peri- and postmenopausal women with insomnia participating in a 6-week, prospective, open-label trial of ramelteon (8 mg), significant improvements in SOL, TST, and sleep efficiency were observed in diary data while gains in sleep quality, sleep impairment, daytime functioning, quality of life, and mood were found in self-report measures. ${ }^{73}$ There was no evidence of tolerance nor rebound insomnia over the course of the trial. Randomized controlled trials are needed to further evaluate the efficacy of ramelteon's use by menopausal women. This recommendation is particularly relevant as many women are now seeking alternative treatments for sleep disturbances in menopause due to concerns about the risks and side effects of the commonly employed hormone replacement treatments.

DSPS is a CRSD in which SOL is delayed in some cases by as much as 2-6 hours. It is characterized by the chronic inability to fall asleep at the desired clock time. ${ }^{74}$ Dahlitz et al. ${ }^{75}$ reported that the administration of $5 \mathrm{mg}$ melatonin advanced sleep onset time by an average of 82 minutes (range 19-124 minutes) and waking time by 117 minutes in patients with DSPS. There is evidence to implicate endogenous melatonin as an important factor in the pathophysiology of CRSD. ${ }^{16}$ The therapeutic potential of ramelteon to treat CRSD was indicated by a study of the phase-shifting capacity of varying doses of the compound in healthy subjects. ${ }^{76}$ Ramelteon, at doses of 1, 2, 4, and $8 \mathrm{mg}$, was administered to 75 adults of the age group 18-45 years for 6 days. Administration of 1,2 , or $4 \mathrm{mg}$ of ramelteon for a period of 4 days was found to promote significant phase advance shifts, assessed by determining the dim light melatonin offset effect ("DLMoff"), ie, the time point when salivary melatonin dropped to below $3 \mathrm{pg} / \mathrm{mL}$ (normally after morning awakening). Shifts of $-7.1 \pm 18.6,-88 \pm 16.6$ ( $P=0.002)$, $-80.5 \pm 14.8(P=0.003)$, and $-90.5 \pm 15.2$ minutes were determined for placebo, 1,2 , and $4 \mathrm{mg}$, respectively $(P=0.001$ for significance ramelteon vs. placebo). Surprisingly, the higher dose of $8 \mathrm{mg}$ ramelteon/day did not cause any significant changes as compared with placebo ( $-27.9 \pm 16.4$ minutes, $P=0.392)-$ an unexpected divergence between the soporific and phase shifting effects according to DLMoff. Although this discrepancy was not resolved, it was concluded that ramelteon nevertheless had the therapeutic potential for treating CRSD. ${ }^{76}$

\section{ADVERSE EFFECTS OF RAMELTEON AND SAFETY}

The incidence of adverse effects of ramelteon, as inferred from subjects' complaints and neurologic parameters, has been reported to be similar to that of placebo. In a study by Erman et al. ${ }^{63}$ the incidence of treatment-emergent adverse events ranged from $8.4 \%$ to $10.7 \%$ among the ramelteon groups and was $8.7 \%$ in the placebo group. The most commonly reported adverse events were headache, somnolence, dizziness, and sore throat. Ramelteon was found to be well tolerated and showed no significant next-day morning psychomotor, memory, or cognitive effects. ${ }^{67,77,78}$ Inasmuch as all currently available BZDs and non-BZD hypnotics cause either addiction, withdrawal symptoms, or trigger rebound insomnia, the relative absence of symptoms following the use of ramelteon underscores its specific advantages for the treatment of insomnia.

In an open-label study, patients with primary insomnia received ramelteon nightly for 1 year. ${ }^{79}$ Subjects aged $\geq 65$ years received ramel- 
teon, $8 \mathrm{mg}$ ( $n=248)$, while those aged 18-64 years received ramelteon, $16 \mathrm{mg}(n=965)$. Ramelteon was associated with sustained improvements in subjective sleep latency, subjective TST, and Clinical Global Impressions. A total of 495 of 1213 subjects $(40.8 \%)$ reported at least one adverse event possibly associated with ramelteon use. The adverse events reported varied considerably $(\mathrm{mild}=30.7 \%$; moderate $=54.2 \%$; and severe $=15.1 \%$ ), the incidence of individual adverse events was low (12.2\% discontinued due to adverse events), and the frequencies of adverse events were similar at months 6 and 12 for both age groups. There were no noteworthy changes in vital signs, physical examinations, clinical chemistry, hematology, or urinalysis values and no electrocardiogram changes to suggest adverse cardiac effects. Endocrine values remained within normal range throughout treatment although consistent statistically significant decreases in free thyroxine (in adults) and free testosterone (in older men) were detected. Duration of menses increased by approximately 1 day. ${ }^{79}$

In a double-blind, placebo-controlled trial of adults (18-45 years) with chronic insomnia to evaluate the effects of ramelteon on endocrine function ramelteon $16 \mathrm{mg}$ or placebo was given nightly for 6 months. ${ }^{77}$ There were no consistent statistically significant differences between treatments on measures of thyroid function (total or free thyroxine, thyroid-stimulating hormone, total triiodothyronine), adrenal function (morning cortisol and adrenocorticotropic hormone), or on most reproductive endocrine measures (luteinizing hormone, follicle-stimulating hormone, estradiol [women], total and free testosterone [men]). Prolactin concentrations were increased overall in women in the ramelteon group compared with placebo $(P=0.003)$. No clinical effects of elevated prolactin were reported; average menstrual cycle length, duration of menses, and ovulation probability did not differ between groups. ${ }^{77}$

Objective criteria in relation to metabolism, other diseases, hepatotoxicity, etc, have been also investigated by Takeda Pharmaceuticals, and ramelteon clearly met a number of such safety requirements that had been fundamental for approval by the Food and Drug Administration (FDA). Nevertheless, it should not be overlooked that the melatonin receptors $\mathrm{MT}_{1}$ and $\mathrm{MT}_{2}$ are not only located in the SCN and do not only regulate the circadian pacemaker. Additional effects via these receptors have to be expected, eg, in cerebral vasomotor control, in immunomodulation, and other hormonal systems, including those involved in reproduction. Reasons for concern in this regard have been discussed elsewhere ${ }^{58,80,81}$ and may become particularly relevant for longterm treatment with the drug.

It should be noted that in May 2008 the EMEA declined to grant marketing authorization for ramel-teon. Following this, Takeda Pharmaceuticals requested a re-examination of the opinion, which was under review at the time of the application withdrawal by the company, based on its current plan to extend the clinical program to address EMEA's questions regarding the medicine's risk-benefit profile.

\section{Some Pharmacodynamic Considerations Concerning Ramelteon}

Taken together, the evidence reviewed above suggests generally that ramelteon, like melatonin, exerts its direct sleep-inducing effects via $\mathrm{MT}_{1}$ receptors located in the $\mathrm{SCN}$, while inducing phase shifting, mainly via $\mathrm{MT}_{2}$ receptors. Because ramelteon's direct soporific effect, as measured by the reduction of SOL (but not the phaseshifting capacity) is indistinguishable at $4 \mathrm{mg}$ and $8 \mathrm{mg}$, ramelteon seems to promote sleep by 
regulating the sleep-wake cycle rather than having a more generalized CNS depressant effect. This is supported by observations that ramelteon does not worsen sleep apnea in insomniacs. ${ }^{82}$

Owing to its potent effect on melatonin receptors in the SCN, ramelteon should accelerate sleep onset by influencing the hypothalamic "sleep-switch" downstream from the $\mathrm{SCN}$, in principle in the same way as melatonin. However, owing to its higher receptor affinity it does so more efficiently. ${ }^{58}$ The sleep-switch model originally proposed by Saper and colleagues $^{82}$ describes "flip-flop" reciprocal inhibitions among sleep-associated activities in the ventrolateral preoptic nucleus and wakefulness associated activities in the locus coeruleus, dorsal raphe, and tuberomammilary nuclei. ${ }^{83,84}$ It has been hypothesized that the prolonged use of ramelteon can result in the desensitization of $\mathrm{MT}_{2}$ receptors in the $\mathrm{SCN} .{ }^{85}$ However, no evidence for such an effect has been provided for ramelteon. From studies of the SCN or immortalized SCN2.2 neurons desensitization and internalization of $\mathrm{MT}_{2}$ is known to occur following exogenous melatonin administration. ${ }^{86,87}$ Whether or not downregulation by ramelteon is stronger or longer-lasting, or even occurs, remains to be demonstrated.

In any event, the studies of ramelteon's actions indicate that this drug, the first melatonin receptor agonist approved by the FDA, represents a good pharmacologic option for the treatment of sleep initiation in insomnia ${ }^{88}$ and thus has a promising future for use in patients with chronic insomnia. ${ }^{58}$

\section{CONCLUSIONS}

Ramelteon has been reported to be a safe hypnotic drug for clinical use in chronic primary insomnia. Clinical studies have shown that ramelteon reduces the SOL and increases
TST. During treatments lasting several weeks, the incidence of adverse effects with ramelteon has been reported to be similar to that of placebo. Ramelteon administration has been shown to be free of other undesired effects such as next day hangover, memory impairment, psychomotor retardation, or cognitive impairment. The hypnotic action of ramelteon is attributed to its effect on melatonergic $\mathrm{MT}_{1}$ and $\mathrm{MT}_{2}$ receptors present in the SCN. It has been also effective in causing phase advances of sleep-wake rhythms in humans, and thus has potential therapeutic value not only in primary insomnia but also in CRSD. No study is available comparing ramelteon versus melatonin in their efficacy.

Other melatonergic agonists, such as agomelatine and tasimelteon, are now on the market or are in the process of being approved by the FDA or EMEA. Moreover, a slow-release preparation of melatonin has just been approved by EMEA for use in elderly patients with sleep disorders. A last important point to be considered is that melatonin-like compounds generally display a modest sleep-inducing effect, quite mild as compared with BZP. Certainly because of the long time in the market and the lack of new alternatives for the treatment of insomnia, the preconception that the consumer has of a sleep pill is that of a strong sleep inducer, something that the melatonin family of compounds will never accomplish. Therefore, a very important educational goal is to change this view on the lack of negative effects (addiction, dependence, etc) that melatonin analogs have in the face of the well-known complications of BZP. ${ }^{89}$

\section{ACKNOWLEDGMENTS}

No funding sources reported.

Competing Interest/Disclosure Statement: S.R. Pandi-Perumal is a stockholder and the President and Chief Executive Officer of 
Somnogen Inc., a New York Corporation. He declares that he has no competing interests that might be perceived to influence the content of this article. All authors declare that they have no proprietary, financial, professional, nor any other personal interest of any nature or kind in any product or services and/or company that could be constructed or considered a potential conflict of interest that might have influenced the views expressed in this manuscript.

\section{REFERENCES}

1. Dijk DJ, Cajochen C. Melatonin and the circadian regulation of sleep initiation, consolidation, structure, and the sleep EEG. J Biol Rhythms. 1997;12:627-635.

2. Reiter RJ, Tan DX, Manchester LC, Qi W. Biochemical reactivity of melatonin with reactive oxygen and nitrogen species: a review of the evidence. Cell Biochem Biophys. 2001;34:237-256.

3. Tan DX, Manchester LC, Terron MP, Flores LJ, Reiter RJ. One molecule, many derivatives: a neverending interaction of melatonin with reactive oxygen and nitrogen species? J Pineal Res. 2007;42: 28-42.

4. Hardeland R. Antioxidative protection by melatonin: multiplicity of mechanisms from radical detoxification to radical avoidance. Endocrine. 2005;27:119-130.

5. Srinivasan V, Maestroni GJM, Cardinali DP, Esquifino AI, Perumal SR, Miller SC. Melatonin, immune function and aging. Immun Aging. 2005;2:17.

6. Cardinali DP, Esquifino AI, Srinivasan V, et al. Melatonin and the immune system in aging. Neuroimmunomodulation. 2008;15:272-278.

7. Reiter RJ. Pineal control of reproduction. Prog Clin Biol Res. 1981;59B:349-355.

8. Brzezinski A, Wurtman RJ. The pineal gland: its possible roles in human reproduction. Obstet Gynecol Surv. 1988;43:197-207.

9. Srinivasan V, Spence DW, Pandi-Perumal SR, Trakht I, Cardinali DP. Therapeutic actions of melatonin in cancer: possible mechanisms. Integr Cancer Ther. 2008;7:189-203.
10. Cos S, Gonzalez A, Martinez-Campa C, Mediavilla MD, Alonso-González C, Sánchez-Barceló EJ. Melatonin as a selective estrogen enzyme modulator. Curr Cancer Drug Targets. 2008;8:691-702.

11. Bartness TJ, Goldman BD. Mammalian pineal melatonin: a clock for all seasons. Experientia. 1989;45:939-945.

12. Armstrong SM. Melatonin and circadian control in mammals. Experientia. 1989;45:932-938.

13. Chase JE, Gidal BE. Melatonin: therapeutic use in sleep disorders. Ann Pharmacother. 1997;31: 1218-1226.

14. Cajochen C, Jewett ME, Dijk DJ. Human circadian melatonin rhythm phase delay during a fixed sleep-wake schedule interspersed with nights of sleep deprivation. J Pineal Res. 2003;35:149-157.

15. Pandi-Perumal SR, Smits M, Spence W et al. Dim light melatonin onset (DLMO): a tool for the analysis of circadian phase in human sleep and chronobiological disorders. Prog Neuropsychopharmacol Biol Psychiatry. 2007;31:1-11.

16. Pandi-Perumal SR, Trakht I, Spence DW, Srinivasan V, Dagan Y, Cardinali DP. The roles of melatonin and light in the pathophysiology and treatment of circadian rhythm sleep disorders. Nat Clin Pract Neurol. 2008;4:436-447.

17. Lieberman HR. Behavior, sleep and melatonin. J Neural Transm Suppl. 1986;21:233-241.

18. Attenburrow ME, Cowen PJ, Sharpley AL. Low dose melatonin improves sleep in healthy middleaged subjects. Psychopharmacology (Berl). 1996; 126:179-181.

19. Sack RL, Lewy AJ, Hughes RJ. Use of melatonin for sleep and circadian rhythm disorders. Ann Med. 1998;30:115-121.

20. Vollrath L, Semm P, Gammel G. Sleep induction by intranasal administration of melatonin. Adv Biosci. 1981;29:327-329.

21. Buysse DJ, Germain A, Moul DE. Diagnosis, epidemiology and consequences of insomnia. Prim Psychiatry. 2005;12:37-44.

22. Foley DJ, Monjan AA, Brown SL, Simonsick EM, Wallace RB, Blazer DG. Sleep complaints among elderly persons: an epidemiologic study of three communities. Sleep. 1995;18:425-432.

23. Ancoli-Israel S, Cooke JR. Prevalence and comorbidity of insomnia and effect on functioning in elderly populations. J Am Geriatr Soc. 2005;53:S264-S271. 
24. Jindal RD, Thase ME. Treatment of insomnia associated with clinical depression. Sleep Med Rev. 2004;8:19-30.

25. Foley D, Ancoli-Israel S, Britz P, Walsh J. Sleep disturbances and chronic disease in older adults: results of the 2003 National Sleep Foundation Sleep in America Survey. J Psychosom Res. 2004;56:497-502.

26. Engle-Friedman M, Bootzin RR, Hazlewood L, Tsao C. An evaluation of behavioral treatments for insomnia in the older adult. J Clin Psychol. 1992;48:77-90.

27. Silber MH. Clinical practice. Chronic insomnia. N Engl J Med. 2005;353:803-810.

28. Kirkwood CK. Management of insomnia. J Am Pharm Assoc (Wash). 1999;39:688-696.

29. O'Hanlon J. Residual effects on memory and psychomotor performance of zaleplon and other hypnotic drugs. Primary Care Companion. J Clin Psychiatry. 2002;4:38-44.

30. Mendelson WB. A review of the evidence for the efficacy and safety of trazodone in insomnia. J Clin Psychiatry. 2005;66:469-476.

31. Leger D, Laudon M, Zisapel N. Nocturnal 6-sulfatoxymelatonin excretion in insomnia and its relation to the response to melatonin replacement therapy. Am J Med. 2004;116:91-95.

32. Zhdanova IV, Wurtman RJ, Lynch HJ, et al. Sleepinducing effects of low doses of melatonin ingested in the evening. Clin Pharmacol Ther. 1995;57:552-558.

33. Zhdanova IV, Wurtman RJ, Morabito C, Piotrovska VR, Lynch HJ. Effects of low oral doses of melatonin, given 2-4 hours before habitual bedtime, on sleep in normal young humans. Sleep. 1996;19:423-431.

34. Gorfine T, Assaf Y, Goshen-Gottstein Y, Yeshurun Y, Zisapel N. Sleep-anticipating effects of melatonin in the human brain. Neuroimage. 2006;31: 410-418.

35. MacFarlane JG, Cleghorn JM, Brown GM, Streiner DL. The effects of exogenous melatonin on the total sleep time and daytime alertness of chronic insomniacs: a preliminary study. Biol Psychiatry. 1991;30:371-376.

36. James SP, Sack DA, Rosenthal NE, Mendelson WB. Mela-tonin administration in insomnia. Neuropsycho-pharmacology. 1990;3:19-23.
37. Ellis CM, Lemmens G, Parkes JD. Melatonin and insomnia. J Sleep Res. 1996;5:61-65.

38. Haimov I, Lavie P, Laudon M, Herer P, Vigder C, Zisapel N. Melatonin replacement therapy of elderly insomniacs. Sleep. 1995;18:598-603.

39. Garfinkel D, Laudon M, Nof D, Zisapel N. Improvement of sleep quality in elderly people by controlledrelease melatonin. Lancet. 1995;346:541-544.

40. Nagtegaal JE, Kerkhof GA, Smits MG, Swart AC, Van Der Meer YG. Delayed sleep phase syndrome: a placebo-controlled cross-over study on the effects of melatonin administered five hours before the individual dim light melatonin onset. J Sleep Res. 1998;7:135-143.

41. Kayumov L, Brown G, Jindal R, Buttoo K, Shapiro CM. A randomized, double-blind, placebocontrolled crossover study of the effect of exogenous melatonin on delayed sleep phase syndrome. Psychosom Med. 2001;63:40-48.

42. Brzezinski A, Vangel MG, Wurtman RJ, et al. Effects of exogenous melatonin on sleep: a meta-analysis. Sleep Med Rev. 2005;9:41-50.

43. von Gall C, Stehle JH, Weaver DR. Mammalian melatonin receptors: molecular biology and signal transduction. Cell Tissue Res. 2002;309:151-162.

44. Dubocovich ML, Rivera-Bermudez MA, Gerdin MJ, Masana MI. Molecular pharmacology, regulation and function of mammalian melatonin receptors. Front Biosci. 2003;8:d1093-d1108.

45. Pandi-Perumal SR, Trakht I, Srinivasan V, et al. Physiological effects of melatonin: role of melatonin receptors and signal transduction pathways. Prog Neurobiol. 2008;85:335-353.

46. McArthur AJ, Hunt AE, Gillette MU. Melatonin action and signal transduction in the rat suprachiasmatic circadian clock: activation of protein kinase $\mathrm{C}$ at dusk and dawn. Endocrinology. 1997;138:627-634.

47. Hunt AE, Al Ghoul WM, Gillette MU, Dubocovich ML. Activation of MT(2) melatonin receptors in rat suprachiasmatic nucleus phase advances the circadian clock. Am J Physiol Cell Physiol. 2001;280:C110-C118.

48. Liu C, Weaver DR, Jin X, et al. Molecular dissection of two distinct actions of melatonin on the suprachiasmatic circadian clock. Neuron. 1997;19: 91-102. 
49. Jin X, von Gall C, Pieschl RL, et al. Targeted disruption of the mouse Mel1b melatonin receptor. Mol Cell Biol. 2003;23:1054-1060.

50. Edgar DM, Dement WC, Fuller CA. Effect of SCN lesions on sleep in squirrel monkeys: evidence for opponent processes in sleep-wake regulation. J Neurosci. 1993;13:1065-1079.

51. Krauchi K, Wirz-Justice A. Circadian clues to sleep onset mechanisms. Neuropsychopharmacology. 2001;25:S92-S96.

52. Stone BM, Turner C, Mills SL, Nicholson AN. Hypnotic activity of melatonin. Sleep. 2000;23: 663-669.

53. Skinner DC, Malpaux B. High melatonin concentrations in third ventricular cerebrospinal fluid are not due to Galen vein blood recirculating through the choroid plexus. Endocrinology. 1999;140: 4399-4405.

54. Turek FW, Gillette MU. Melatonin, sleep, and circadian rhythms: rationale for development of specific melatonin agonists. Sleep Med. 2004;5: 523-532.

55. Mendelson WB. A critical evaluation of the hypnotic efficacy of melatonin. Sleep. 1997;20: 916-919.

56. Kato K, Hirai K, Nishiyama K et al. Neurochemical properties of ramelteon (TAK-375), a selective MT1/MT2 receptor agonist. Neuropharmacology. 2005;48:301-310.

57. Miyamoto M. Pharmacology of ramelteon, a selective MT1/MT2 receptor agonist: a novel therapeutic drug for sleep disorders. CNS Neurosci Ther. 2009;15:32-51.

58. Hardeland R, Poeggeler B, Srinivasan V, Trakht I, Pandi-Perumal SR, Cardinali DP. Melatonergic drugs in clinical practice. Arzneimittelforschung. 2008;58:1-10.

59. Stevenson S, Bryson S, Amayke D, Hibberd M. Study to investigate the absolute bioavailability of a single oral dose of ramelteon (TAK-375) in healthy male subjects. Clin Pharmacol Ther. 2004;75:P22.

60. Greenblatt DJ, Harmatz JS, Karim A. Age and gender effects on the pharmacokinetics and pharmacodynamics of ramelteon, a hypnotic agent acting via melatonin receptors MT1 and MT2. J Clin Pharmacol. 2007;47:485-496.
61. Yukuhiro N, Kimura H, Nishikawa H, Ohkawa S, Yoshikubo S, Miyamoto M. Effects of ramelteon (TAK-375) on nocturnal sleep in freely moving monkeys. Brain Res. 2004;1027:59-66.

62. France CP, Weltman RH, Koek W, Cruz CM, McMahon LR. Acute and chronic effects of ramelteon in rhesus monkeys (Macaca mulatta): dependence liability studies. Behav Neurosci. 2006;120:535-541.

63. Erman M, Seiden D, Zammit G, Sainati S, Zhang J. An efficacy, safety, and dose-response study of Ramelteon in patients with chronic primary insomnia. Sleep Med. 2006;7:17-24.

64. Roth T, Seiden D, Sainati S, Wang-Weigand S, Zhang J, Zee P. Effects of ramelteon on patientreported sleep latency in older adults with chronic insomnia. Sleep Med. 2006;7:312-318.

65. Roth T, Seiden D, Wang-Weigand S, Zhang J. A 2-night, 3-period, crossover study of ramelteon's efficacy and safety in older adults with chronic insomnia. Curr Med Res Opin. 2007;23:1005-1014.

66. Zammit G, Erman M, Wang-Weigand S, Sainati S, Zhang J, Roth T. Evaluation of the efficacy and safety of ramelteon in subjects with chronic insomnia. J Clin Sleep Med. 2007;3:495-504.

67. Zammit G, Schwartz H, Roth T, Wang-Weigand S, Sainati S, Zhang J. The effects of ramelteon in a first-night model of transient insomnia. Sleep Med. 2009;10:55-59.

68. Mini L, Wang-Weigand S, Zhang J. Ramelteon 8 $\mathrm{mg} / \mathrm{d}$ versus placebo in patients with chronic insomnia: post hoc analysis of a 5-week trial using $50 \%$ or greater reduction in latency to persistent sleep as a measure of treatment effect. Clin Ther. 2008;30:1316-1323.

69. Simpson D, Curran MP. Ramelteon: a review of its use in insomnia. Drugs. 2008;68:1901-1919.

70. Wang-Weigand S, McCue M, Ogrinc F, Mini L. Effects of ramelteon $8 \mathrm{mg}$ on objective sleep latency in adults with chronic insomnia on nights 1 and 2: pooled analysis. Curr Med Res Opin. 2009;25: 1209-1213.

71. Gross PK, Nourse R, Wasser TE. Ramelteon for insomnia symptoms in a community sample of adults with generalized anxiety disorder: an open label study. J Clin Sleep Med. 2009;5:28-33.

72. Mayer G, Wang-Weigand S, Roth-Schechter B, Lehmann R, Staner C, Partinen M. Efficacy and safety of 6-month nightly ramelteon administra- 
tion in adults with chronic primary insomnia. Sleep. 2009;32:351-360.

73. Dobkin RD, Menza M, Bienfait KL, Allen LA, Marin H, Gara MA. Ramelteon for the treatment of insomnia in menopausal women. Menopause Int. 2009;15:13-18.

74. Regestein QR, Monk TH. Delayed sleep phase syndrome: a review of its clinical aspects. Am J Psychiatry. 1995;152:602-608.

75. Dahlitz M, Alvarez B, Vignau J, English J, Arendt J, Parkes JD. Delayed sleep phase syndrome response to melatonin. Lancet. 1991;337:1121-1124.

76. Richardson GS, Zee PC, Wang-Weigand S, Rodriguez L, Peng X. Circadian phase-shifting effects of repeated ramelteon administration in healthy adults. J Clin Sleep Med. 2008;4:456-461.

77. Richardson G, Wang-Weigand S. Effects of longterm exposure to ramelteon, a melatonin receptor agonist, on endocrine function in adults with chronic insomnia. Hum Psychopharmacol. 2009;24: 103-111.

78. Zammit G, Wang-Weigand S, Rosenthal M, Peng X. Effect of ramelteon on middle-of-the-night balance in older adults with chronic insomnia. J Clin Sleep Med. 2009;5:34-40.

79. Richardson GS, Zammit G, Wang-Weigand S, Zhang J. Safety and subjective sleep effects of ramelteon administration in adults and older adults with chronic primary insomnia: a 1-year, open-label study. J Clin Psychiatry. 2009;70: 467-476.

80. Srinivasan V, Pandi-Perumal SR, Trahkt I et al. Melatonin and melatonergic drugs on sleep: possible mechanisms of action. Int $\mathrm{J}$ Neurosci. 2009;119:821-846.
81. Kryger M, Wang-Weigand S, Roth T. Safety of ramelteon in individuals with mild to moderate obstructive sleep apnea. Sleep Breath. 2007;11: 159-164.

82. Saper CB, Scammell TE, Lu J. Hypothalamic regulation of sleep and circadian rhythms. Nature. 2005;437:1257-1263.

83. Fuller PM, Gooley JJ, Saper CB. Neurobiology of the sleep-wake cycle: sleep architecture, circadian regulation, and regulatory feedback. J Biol Rhythms. 2006;21:482-493.

84. Wurtman R. Ramelteon: a novel treatment for the treatment of insomnia. Expert Rev Neurother. 2006;6:957-964.

85. Gerdin MJ, Masana MI, Ren D, Miller RJ, Dubocovich ML. Short-term exposure to melatonin differentially affects the functional sensitivity and trafficking of the hMT1 and hMT2 melatonin receptors. J Pharmacol Exp Ther. 2003;304: 931-939.

86. Gerdin MJ, Masana MI, Rivera-Bermudez MA, et al. Melatonin desensitizes endogenous MT2 melatonin receptors in the rat suprachiasmatic nucleus: relevance for defining the periods of sensitivity of the mammalian circadian clock to melatonin. FASEB J. 2004;18:1646-1656.

87. Borja NL, Daniel KL. Ramelteon for the treatment of insomnia. Clin Ther. 2006;28:1540-1555.

88. Bellon A. Searching for new options for treating insomnia: are melatonin and ramelteon beneficial? J Psychiatr Pract. 2006;12:229-243.

89. Cardinali DP, Golombek DA. Let there be sleepon time. Lancet. 2009;373:439-441. 